\title{
Desjudicialização e atos probatórios concertados entre as esferas judicial e extrajudicial: a cooperação interinstitucional online prevista na resolução 350 do CNJ
}

Flávia Pereira Hill ${ }^{1}$

Humberto Dalla Bernardina de Pinho

\section{Resumo}

O texto trata da desjudicialização e da valorização da atividade extrajudicial no Código de Processo Civil de 2015. Examina, ainda, a cooperação entre as esferas judicial e extrajudicial, a necessidade de desenvolvimento do "triplo C": Cooperação, Complementaridade e Coordenação. Por fim, é analisada a Resolução n ${ }^{\circ} 350$ do CNJ e a cooperação interinstitucional online em matéria probatória.

Palavras-chave: Desjudicialização; Cooperação; Online; Atos probatórios.

\begin{abstract}
The text deals with the de-judicialization and enhancement of extrajudicial activity in the 2015 Civil Procedure Code. It also examines the cooperation between the judicial and extrajudicial spheres, the need to develop the "triple C": Cooperation, Complementarity and Coordination. Finally, it analyzes the Resolution n 350 of the National Council of Justice and online interinstitutional cooperation in evidentiary matters are analyzed.
\end{abstract}

Keywords: Cooperation; Evidence; Online; De-judicialization.

\footnotetext{
${ }^{1}$ Doutora e Mestre em Direito Processual pela Universidade do Estado do Rio de Janeiro (UERJ). Professora Adjunta de Direito Processual Civil da Universidade do Estado do Rio de Janeiro (UERJ). Pesquisadora visitante da Università degli Studi di Torino, Itália. Tabeliã.

2 Professor Titular de Direito Processual Civil na UERJ e na Estácio. Procurador de Justiça no estado do Rio de Janeiro.
} 


\section{A DESJUDICIALIZAÇÃO E A VALORIZAÇÃO DA ATIVIDADE EXTRAJUDICIAL NO CPC/2015}

Cada diploma retrata, inexoravelmente, o contexto histórico em que foi editado. As codificações processuais, em especial, por se destinarem a prever os mecanismos voltados a resguardar ou restaurar, concretamente, a esfera jurídica dos jurisdicionados, em caso, respectivamente, de ameaça ou violação a direitos, devem retratar, com ainda maior sensibilidade, as características da sociedade à qual se dirigem.

Enquanto o artigo $5^{\circ}$, inciso XXXV, da Constituição Federal de 1988 prevê que "a lei não excluirá da apreciação do Poder Judiciário lesão ou ameaça a direito", o artigo $3^{\circ}$ do Código de Processo Civil preconiza que "não se excluirá da apreciação jurisdicional ameaça ou lesão a direito".

Portanto, a diferença no texto legal entre a Constituição, editada nos idos de 1988, e o CPC, editado em 2015, não é casual nem tampouco irrelevante ${ }^{3}$. Denota as profundas mudanças ocorridas no seio de nossa sociedade e de nosso sistema de justiça à medida em que atravessávamos o umbral de um novo século.

Passamos da busca por garantir o acesso ao Judiciário para a busca por garantir o acesso à justiça. Isso revela mudanças profundas no conceito de jurisdição, que deixa de ser vista como monopólio do Poder Judiciário. O aspecto subjetivo deixa de ser um elemento indeclinável para a caracterização da jurisdição.

Isso porque a atividade não perde a sua essência exclusivamente em razão de ter sido praticada intra ou extra muros, ou seja, dentro ou fora do Poder Judiciário. O foco precisa estar, pois, na atividade desempenhada e não em quem a presta.

\footnotetext{
3 “ (...) o art. $3^{\circ}$ do NCPC, ao se referir a apreciação jurisdicional, vai além do Poder Judiciário e da resolução de controvérsias pela substitutividade. O dispositivo passa a permitir outras formas positivas de composição, pautadas no dever de cooperação das partes e envolvendo outros atores. Desse modo, a jurisdição, outrora exclusiva do Poder Judiciário, pode ser exercida por serventias extrajudiciais ou por câmaras comunitárias, centros ou mesmo conciliadores e mediadores extrajudiciais. (...) A jurisdição é essencialmente uma função estatal. Por isso, em momentos históricos diversos, desde a Antiguidade, passando pelas Idades Média, Moderna e chegando à contemporânea, o Estado, invariavelmente, chamou para si o monopólio da jurisdição, sistematizando-a, a partir de Luiz XIV. A atuação jurisdicional, então, era um poderoso mecanismo para assegurar o cumprimento das leis. No entanto, Leonardo Greco admite que a jurisdição não precisa ser, necessariamente, uma função estatal. É claro que não se pode simplesmente desatrelar a jurisdição do Estado, até porque, em maior ou menor grau, a dependência do Estado existe, principalmente para se alcançar o cumprimento da decisão não estatal. Por outro lado, podemos pensar no exercício dessa função por outros órgãos do Estado ou por agentes privados. Nesta ótica, percebe-se o fenômeno da desjudicialização enquanto ferramenta de racionalização da prestação jurisdicional e ajuste ao cenário contemporâneo, o que leva, necessariamente, à releitura, à atualização, ou ainda a um redimensionamento da garantia constitucional à luz dos princípios da efetividade e da adequação.” PINHO, Humberto Dalla Bernardina de. "A releitura do princípio do acesso à justiça e o necessário redimensionamento da intervenção judicial na resolução dos conflitos na contemporaneidade”. In Revista Jurídica Luso-brasileira. Ano 5. Número 3. 209. pp. $791-830$.
} 
No século XX, o sistema de justiça encontrava-se precipuamente organizado segundo a tríade Magistratura-Ministério Público-Advocacia Pública/Privada, ao passo que, no século XXI, o cenário se mostra mais complexo e multifacetado. Seja a partir do ingresso de outros personagens no centro da cena - como é o caso de mediadores, conciliadores, árbitros e delegatários de serventias extrajudiciais -, cuja atuação pressupõe uma participação mais ativa e próxima do jurisdicionado, seja com a valorização de institutos como o amicus curiae e os negócios jurídicos processuais no bojo do processo judicial.

A evolução dos meios de comunicação e da tecnologia também contribuiu decisivamente para que as pessoas disponham, hoje, de um acesso mais fácil às informações. Noticia-se que $74 \%$ da população brasileira dispunha de acesso à internet em $2018^{4}$.

Tanto é assim que um dos desafios atuais consiste em procurar conter as chamadas "fake News", um "efeito colateral" claro da ampla difusão de informações - muitas delas inconfiáveis - na contemporaneidade.

O homem médio é mais bem informado nos dias de hoje do que há 30 anos atrás. Essa constatação influi inexoravelmente na análise do acesso à justiça. Como Paulo Cezar Pinheiro Carneiro alerta, com propriedade, o acesso à informação é o primeiro requisito do acesso à justiça $^{5}$. Sem conhecimento de seus direitos e sobre como defendê-los, fatalmente o jurisdicionado não possui as condições mínimas para fazer valer, concretamente, a garantia do acesso à justiça. $\mathrm{O}$ acesso à informação consiste, pois, em condição inexorável do acesso à justiça.

A maior consciência de seus direitos por parte da sociedade decorrente da ampliação da difusão de informações permite que a sociedade possa, passados mais de 30 anos de vigência da Constituição-cidadã, exercer uma participação democrática mais madura e pujante, inclusive no sistema de justiça.

Nesse contexto, temos o avanço do fenômeno da desjudicialização, segundo o qual litígios ou atos da vida civil que dependeriam necessariamente da intervenção judicial para a sua solução, passam a poder ser realizados perante agentes externos ao Poder Judiciário, que não fazem parte de seu quadro de servidores. Trata-se, em suma, da consecução do acesso à justiça fora do Poder Judiciário, ou seja, do acesso à justiça extra muros.

O Código de Processo Civil de 2015, com coerência, deixa clara a importância da atuação dos cartórios extrajudiciais para o sistema de justiça contemporâneo, em duas vertentes:

\footnotetext{
${ }^{4}$ VALENTE, Jonas. Agência Brasil. Brasil tem 134 milhões de usuários de internet, aponta pesquisa. Disponível no endereço eletrônico: https://agenciabrasil.ebc.com.br/geral/noticia/2020-05/brasil-tem-134-milhoes-deusuarios-de-internet-aponta-pesquisa Consulta realizada em 05/08/2020.

${ }^{5}$ CARNEIRO, Paulo Cezar Pinheiro. "Acesso à justiça: Juizados Especiais Cíveis e Ação Civil Pública. Uma nova sistematização da Teoria Geral do Processo.” 2. Ed. Rio de Janeiro: Forense, 2000. P. 57.
} 
i) nos processos extrajudiciais (desjudicialização): ao assumir funções até então exclusivas do Poder Judiciário, como é o caso, ad exemplum tantum, da mediação e da conciliação (não apenas extrajudicial, mas também diante da possibilidade de os cartórios judiciais atuarem na mediação judicial, como Cejuscs - Centros Judiciários de solução de conflitos e cidadania, mediante convênio, conforme Recomendação no 28/2018 do CNJ) e dos procedimentos extrajudiciais de jurisdição voluntária.

ii) nos processos judiciais: mediante a prática de atos relevantes para o exercício da jurisdição estatal, tais como a previsão da Ata Notarial como meio de prova típico (artigo 384, CPC/15), a possibilidade de averbação premonitória (artigo 828, CPC/15), o protesto de decisão judicial transitada em julgado (artigo 517, CPC/15), e a penhora de imóvel devidamente matriculado por termo nos autos (artigo $845, \S 1^{\circ}, \mathrm{CPC} / 15$ ).

O paradigma do acesso ao Poder Judiciário cede lugar, portanto, ao paradigma da Justiça Multiportas $^{6}$, em que novos agentes são convocados a oferecer ao jurisdicionado outros mecanismos igualmente legítimos e adequados para a solução dos litígios (ou o exercício da jurisdição voluntária) e que se colocam ao lado da adjudicação estatal. Abrem-se vários possíveis caminhos para se chegar, no Estado Democrático de Direito contemporâneo, à pacificação com justiça.

A nova concepção de jurisdição compartilhada entre Poder Judiciário e os novos núcleos decisórios, especialmente os delegatários de serventias extrajudiciais, coloca em evidência a necessidade premente de que, para bem prestar a jurisdição na contemporaneidade, se desenvolva crescente cooperação entre as esferas judicial e extrajudicial, mormente se considerarmos o teor da Resolução no 350/2020 do Conselho Nacional de justiça, que, com propriedade, fomenta a cooperação interinstitucional, conforme nos propomos a refletir no presente trabalho.

\section{COOPERAÇÃO ENTRE AS ESFERAS JUDICIAL E EXTRAJUDICIAL E NECESSIDADE DE DESENVOLVIMENTO DO "TRIPLO C": COOPERAÇÃO, COMPLEMENTARIDADE E COORDENAÇÃO}

A reconfiguração, pelo legislador, do papel dos delegatários de serventias extrajudiciais, através da previsão de nova funções em decorrência da desjudicialização e da concepção da Justiça Multiportas em nosso país, precisa vir acompanhada de uma nova dinâmica na interação entre os operadores do Direito, especialmente nas relações entre o Poder Judiciário e os cartórios extrajudiciais.

\footnotetext{
${ }^{6}$ GOLDBERG, Stephen B. SANDER, Frank E. A. ROGERGS, Nancy H. COLE, Sarah Rudolph. Dispute Resolution. 4. Ed. Nova York: Aspen Publishers. 2003. p. 07.
} 
É indispensável seja desenvolvido o que chamamos de "triplo C": Cooperação, Complementaridade e Coordenação. De fato, assim como é de todo útil e necessário que as diferentes instâncias e esferas do Poder Judiciário cooperem entre si e coordenem a sua atuação ${ }^{7}$, para otimizá-la e potencializá-la, o mesmo acontecendo entre os órgãos do Ministério Público, também deve estar em franca expansão a integração e a coordenação entre as esferas judicial e extrajudicial ${ }^{8}$.

Cooperação importa na adoção de uma conduta colaborativa, que resulte em maior proveito para a atuação do outro profissional, ou seja, optar pela adoção de uma conduta que não só se volte a se desincumbir de seu mister, mas também se volte a potencializar, de forma construtiva, a atuação dos demais profissionais envolvidos. Podemos exemplificar com a conduta do delegatário de serventia extrajudicial que, ao receber um mandado judicial que careça da indicação de elemento indispensável para a realização do registro, dedica-se a examinar a documentação anexa, a fim de buscar identificar se o referido elemento se encontra descrito em alguma peça processual acostada, em vez de simplesmente expedir ofício solicitando seja sanada a omissão.

Simetricamente, a fiscalização exercida pelas Corregedorias dos tribunais locais e da Corregedoria Nacional de Justiça deve igualmente se pautar pela cooperação, nesse novo contexto do sistema de justiça. Além da conduta sancionatória e repressiva, voltada a atuar $a$ posteriori, afigura-se de todo consentânea com a cooperação entre as esferas judicial e extrajudicial a fiscalização preventiva e construtiva, voltada a, mediante troca perene de impressões, experiências e dificuldades de parte a parte, permitir sejam prestados esclarecimentos e indicadas as formas mais adequadas de desenvolver as atividades extrajudiciais, especialmente no caso da assunção de novas funções extrajudiciais em decorrência da desjudicialização, que implica reformulações significativas na praxe cartorária. Cuida-se, pois, de uma fiscalização prospectiva e com caráter instrutivo. Essa perspectiva da fiscalização passa pela noção, desenvolvida ao longo do presente estudo, de que a administração da justiça, na atualidade, é compartilhada por vários agentes, incluindo os delegatários dos cartórios extrajudiciais e que a colaboração entre as Corregedorias e tais serventias, de forma construtiva, ensejará ganhos em efetividade e eficiência, reduzindo a incursão em condutas consideradas inadequadas e, por conseguinte, resultando em maior grau de satisfação por parte do jurisdicionado, com redução do dispêndio de tempo e recursos.

\footnotetext{
${ }^{7}$ DIDIER JUNIOR, Fredie. Cooperação judiciária nacional: esboço de uma teoria para o Direito brasileiro (arts. 67-69, CPC). Salvador: Jus Podivm. 2020.

${ }^{8}$ Nesse sentido, ao tratar das interações entre árbitros e juízes, Maria Gabriela Campos defende a importância da cooperação entre ambos, afirmando haver entre eles relação de "complementaridade e cooperação". Da mesma forma que, com propriedade, aduz a autora que "não existe uma contraposição de papeis e interesses entre o juiz arbitral e o juiz estatal", o mesmo se dá entre o juiz estatal e o delegatário de cartório extrajudicial, tendo em vista que todos buscam o adequado e efetivo exercício da função jurisdicional no sistema de justiça pátrio. CAMPOS, Maria Gabriela. O compartilhamento de competências no processo civil: um estudo do sistema de competências sob o paradigma da cooperação nacional. Salvador: Jus Podivm. 2020. P. 140.
} 
Complementaridade se relaciona com a noção de que cada profissão jurídica reúne prerrogativas e âmbito de atuação delimitados, exercendo papeis diversos, embora complementares, no sistema de justiça. Portanto, para que seja prestada jurisdição, com efetividade e eficiência, na atualidade, faz-se necessário enxergar o sistema de justiça em sua inteireza. Cada profissão jurídica é, pois, uma engrenagem, com função própria, integrante da grande máquina que é o sistema de justiça; especialmente nos dias de hoje, em que prevalece a noção de "pluralismo decisório" ou "jurisdição compartilhada", nas precisas expressões trazidas por Rodolfo de Camargo Mancuso ${ }^{9}$. Para que essa máquina funcione a contento, com a eficiência que a sociedade espera e clama, urge que cada engrenagem exerça e compreenda a sua função não apenas isoladamente, mas também as demais, e se veja como parte de um todo. Os alemães designam essa perspectiva como grupo de trabalho (Arbeitsgemeinschaft), em que os profissionais do Direito se veem e atuam como um grupo que compartilha os mesmos objetivos, notadamente, no caso do sistema de justiça, prestar jurisdição com efetividade à sociedade a que serve.

Sendo assim, o magistrado compreende que não lhe compete lavrar atas notariais, escrituras públicas, lavrar registros e averbações de toda sorte, desde protesto de sentenças, títulos e documentos de dívidas, passando por nascimentos, óbitos e casamentos, até transferência de direitos reais, arrestos e penhoras, embora saiba que tais atos assumem crescente relevância para a jurisdição estatal, seja para fins probatórios ou executivos. Acrescente-se, por outro lado, que, com a desjudicialização, as novas funções assumidas pelos cartórios extrajudiciais têm o condão de reduzir significativamente a sobrecarga do Poder Judiciário, de modo a lhe pedir que possa desempenhar, com maior presteza e acuidade, a função jurisdicional no conjunto (menor) de ações que lhe serão dirigidas.

Por conseguinte, se cada profissão jurídica exerce um papel delimitado, ela depende das demais para que, complementarmente, atinjam os objetivos a que se propõem, especialmente atender o jurisdicionado em seu legítimo pleito.

Coordenação, por seu turno, é um consectário da noção de complementaridade, na medida em que os profissionais do Direito, cientes de que são engrenagens do sistema de justiça e de que a sua atuação se soma e é complementada pela atuação das demais profissões, passam a, premidos por essa visão global do sistema de justiça, estar atentos à atuação dos outros para com eles coordenar a sua própria atuação. Trata-se da ideia de que cada engrenagem opere da forma e no tempo corretos para permitir que as outras engrenagens desenvolvam as suas respectivas tarefas e a máquina, ao final, funcione a contento. Assemelha-se, ainda, a uma orquestra, cuja apresentação primorosa depende da atuação coordenada de seus músicos, cada qual manejando, com maestria, o instrumento em que é versado, de modo que todos os sons contemplados na partitura estejam magistralmente representados no palco, com ritmo, precisão e arte.

\footnotetext{
${ }^{9}$ MANCUSO, Rodolfo de Camargo. A resolução dos conflitos e a função judicial no contemporâneo Estado de Direito. 2. ed. São Paulo: Revista dos Tribunais. 2014. P. 171.
} 
A cooperação entre os cartórios extrajudiciais já é uma realidade, especialmente em razão da informatização dos serviços prestados. Há plataformas online congregando todos os cartórios do país em cada atribuição, como, ad exemplum tantum, as plataformas Central de Registro Civil (CRC Nacional) ${ }^{10}$, Central Nacional de Protesto de Títulos (Cenprot) ${ }^{11}$, Central de Registro de Imóveis do Brasil ${ }^{12}$ e o E-notariado ${ }^{13}$ (Provimento ${ }^{\circ} 100$ do CNJ).

Os cartórios de Registro Civil de Pessoas Naturais de todo país estão em permanente contato entre si, através da plataforma acima mencionada, para diversas finalidades, dentre as quais sobressai a realização das comunicações previstas no artigo 106 da Lei Federal $\mathrm{n}^{\circ}$ 6.015/973. De fato, a cada novo registro lavrado, é necessário comunicá-lo aos cartórios onde foram lavrados os registros anteriores, a fim de que estes possam fazer a respectiva anotação à margem do termo (remissões recíprocas). Por exemplo, o registro do óbito de uma pessoa natural precisa ser comunicado ao cartório onde foi lavrado o registro de seu casamento (se o de cujus for casado, separado ou divorciado) ou de seu nascimento (se o obituado for solteiro). Essa comunicação é de suma importância, inclusive, para evitar fraudes e ilícitos penais, como o recebimento indevido de salários, pensões e outros proventos (art. 171, §3º $\mathrm{CP}$ ), tendo em vista que, caso seja solicitada a expedição de certidão segunda via do registro de casamento ou nascimento do obituado, esta conterá, em suas observações, a informação acerca da anotação do registro de seu óbito. O mesmo se diga a respeito da anotação do registro de casamento à margem do registro de nascimento dos nubentes, a fim de evitar, dentre outros ilícitos penais, o cometimento de bigamia (artigo 235, CP).

Na usucapião extrajudicial, há cooperação entre o Registro de Imóveis, que conduz o procedimento, o Tabelionato de Notas, responsável pela lavratura da Ata Notarial, documento fundamental para a obtenção da providência almejada, e o Registro de Títulos e Documentos, com atribuição para realizar as notificações extrajudiciais dos entes públicos (artigo 216-A da Lei Federal no 6.015/1973).

Acrescente-se haver convênios entre cartórios de diferentes atribuições para melhor atender o usuário, como o convênio firmado entre a Associação de Registradores de Imóveis de São Paulo e a Associação de Registradores Civis de Pessoas Naturais (Ofícios da Cidadania) de São Paulo para recepção de títulos e demais providências de monitoramento quanto ao

10 CENTRAL DE REGISTRO CIVIL Disponível no endereço eletrônico: https://sistema.registrocivil.org.br/portal/?CFID=2635991\&CFTOKEN=43a371d38cb7ba0c-20A4D228-FEB145F8-12564FF062C21FCB Consulta realizada em 17/08/2020.

11 CENTRAL NACIONAL DE PROTESTO DE TÍTULOS. Disponível no endereço eletrônico: https://site.cenprotnacional.org.br/ Consulta realizada em 17/08/2020.

12 CENTRAL DE REGISTRO DE IMÓVEIS DO BRASIL. Disponível no endereço eletrônico: https://www.registrodeimoveis.org.br/ Consulta realizada em 17/08/2020.

${ }^{13}$ E-NOTARIADO. Disponível no endereço eletrônico: https://www.e-notariado.org.br/ Consulta realizada em $17 / 08 / 2020$. 
registro imobiliário ou à devolução com nota de exigência, e homologado pela CorregedoriaGeral de Justiça de São Paulo, em 16/04/202014.

Portanto, se, hoje, muito se avançou na cooperação entre os diferentes órgãos integrantes do Poder Judiciário, de um lado, assim como entre os cartórios extrajudiciais, de outro, faz-se necessário avançar, de modo a estreitar a rede de cooperação recíproca entre as esferas judicial e extrajudicial.

A todas as luzes, o "triplo C", que mencionamos acima, é necessário na relação entre as esferas judicial e extrajudicial, como o próprio CPC/2015 já indica ao prever expressamente a carta arbitral (artigo 260, $\$ 3^{\circ}, \mathrm{CPC} 15$ ). Entendemos, contudo, que ela precisa ser expandida, com fulcro no artigo 15 do CPC/2015, de modo que seja estabelecido um canal de diálogo e cooperação entre os juízes e os cartórios extrajudiciais.

\section{A RESOLUÇÃO $\mathbf{N}^{\circ} \quad 350$ DO CNJ E A COOPERAÇÃO INTERINSTITUCIONAL ONLINE EM MATÉRIA PROBATÓRIA}

O fenômeno da desjudicialização desafia os operadores do Direito a reler diversos institutos seculares de Direito Processual, dentre os quais sobressai a cooperação judiciária. Se, em um sistema de justiça centrado no Poder Judiciário, fazia sentido restringir a cooperação ao âmbito dos órgãos judiciários, no dias atuais, com a expansão da desjudicialização e a reconfiguração do sistema de justiça, com vistas a abarcar outros núcleos decisórios, como vimos em momento anterior do presente trabalho, faz-se necessário expandir o aludido conceito, a bem da boa administração da justiça e da prestação jurisdicional adequada e eficiente.

Com efeito, Fredie Didier Junior, ao conceituar a cooperação judiciária nacional, expande o seu espectro para além dos órgãos integrantes do Poder Judiciário:

\footnotetext{
“A cooperação judiciária nacional é o complexo de instrumentos e atos jurídicos pelos quais os órgãos judiciários brasileiros podem interagir entre si, com tribunais arbitrais ou órgãos administrativos, com o propósito de colaboração para o processamento e/ou julgamento de casos e, de modo mais genérico, para a própria administração da justiça, por meio de compartilhamento ou delegação de competência, prática de atos processuais, centralização de processos, produção de prova comum, gestão de processos e de outras técnicas destinadas ao aprimoramento da prestação jurisdicional no Brasil". 15
}

14 CORREGEDORIA-GERAL DE JUSTIÇA DO ESTADO DE SÃO PAULO. Processo $\mathrm{n}^{\circ}$ 2020/38240.https://infographya.com/files/20200417_DECISAO__CONVENIO_ARISP_ARPENSP.pdf

Consulta realizada em 17/08/2020.

${ }^{15}$ DIDIER JUNIOR, Fredie. Op. cit. pp. 61-62. 
O autor prossegue, sustentando, com razão, que "as normas sobre cooperação judiciária servem a qualquer espécie de processo - civil, eleitoral ou trabalhista (art. 15, CPC)", acrescentando que a Recomendação no 38/2011 do Conselho Nacional de Justiça admite "a cooperação judiciária em todos os tipos de "incidentes, procedimentos e ritos processuais"” 16.

Firme nessa premissa, o Conselho Nacional de Justiça foi além ao editar, em 2020, a Resolução $n^{\circ} 350$, através da qual estabelece diretrizes e procedimentos sobre a cooperação judiciária nacional. Logo em seu artigo $1^{\circ}$, o Provimento expande o conceito de cooperação judiciária, que passa a abranger a cooperação interinstitucional entre os órgãos do Poder Judiciário e outras instituições e entidades, integrantes ou não do sistema de justiça, que possam, direta ou indiretamente, contribuir para a administração da justiça.

O Conselho Nacional de Justiça tem o inegável mérito de, na Resolução no 350, se mostrar sensível à nova configuração do sistema de justiça brasileiro, que transcende os confins do Poder Judiciário, para disponibilizar mecanismos de cooperação judiciária entre os órgãos judiciais e os novos núcleos decisórios, notadamente as serventias extrajudiciais, no contexto da desjudicialização.

A respeito da cooperação judiciária em matéria probatória, merece destaque que o Provimento 350 autoriza, nos incisos II, VI e VII, respectivamente, a prática de atos voltados à troca de informações relevantes para a solução dos processos, à obtenção e à apresentação de provas, à coleta de depoimentos e aos meios para o compartilhamento de seu teor, à produção de prova única relativa a fato comum, dentre outros.

Acrescente-se que o artigo $8^{\circ}, \S^{\circ}$, da Resolução $n^{\circ} 350$ estatui, com correção, que os atos de cooperação devem ser prioritariamente realizados através dos meios eletrônicos ${ }^{17}$, de modo a colocar as novas tecnologias em favor da deformalização e da celeridade, ou seja, da eficiência na prestação jurisdicional.

As serventias extrajudiciais encontram-se informatizadas, o que restou demonstrado a partir da rápida colocação das novas tecnologias à serviço da continuidade na prestação dos serviços extrajudiciais em meio às severas restrições de deslocamento em decorrência da pandemia de Covid-19, tais como a implementação do E-notariado (Provimento $\mathrm{n}^{\circ}$ 100/2020 do CNJ), a realização de casamentos por videoconferência (artigo 24 do Provimento $n^{\circ}$ 31/2020 da CGJ RJ), o envio eletrônico dos documentos necessários para a lavratura de registros de nascimentos e de óbito (Provimento n ${ }^{\circ}$ 93/2020 do CNJ), a emissão de certidões digitais através

\footnotetext{
${ }^{16}$ Idem. p. 71.

${ }^{17}$ No mesmo sentido, defendendo que os atos de cooperação sejam preferencialmente praticados eletronicamente, tendo em vista que o artigo 69 do CPC/2015 dispensa forma específica. LUNARDI, Thais Amoroso Paschoal. Coletivização da prova. Técnicas de produção coletiva da prova e seus reflexos na esfera individual. Tese de Doutorado em Direito das Relações Sociais no Programa de Pós- Graduação da Faculdade de Direito da Universidade Federal do Paraná. 2018. P. 169.
} 
dos portais eletrônicos, dentre os quais a Central de Registro Civil - CRC (artigo 21 do Provimento $n^{\circ}$ 31/2020 da CGJ RJ).

Com efeito, a Resolução $\mathrm{n}^{\circ} 350$ do $\mathrm{CNJ}$ cria condições para que órgãos do Poder Judiciário e serventias extrajudiciais celebrem atos concertados com vistas a permitir que as provas produzidas nos processos extrajudiciais possam ser validamente empregadas no convencimento judicial em processos judiciais correlatos. Inúmeros são os exemplos práticos que demonstram a grande utilidade do emprego de tais mecanismos na rotina forense.

Um exemplo emblemático consiste no registro de nascimento após decorrido o prazo previsto no artigos 50 e 52, $2^{\circ}$, da Lei Federal $n^{\circ}$ 6.015/1973, especialmente de maiores de 12 anos, que, até 2008 , dependia inexoravelmente de prévia autorização judicial para ser lavrado ${ }^{18}$.

A necessidade de instauração de processo judicial tinha como escopo evitar a duplicidade do registro, na medida em que cabia ao magistrado aferir a inexistência de registro anterior de nascimento, para que, somente após, autorizasse a lavratura, pelo cartório, do respectivo registro tardio.

Em um país com dimensões continentais como o nosso e com disparidades sociais e culturais imensas, não é raro que o registro de nascimento seja tardio. Com a exigência de autorização judicial prévia, aumentavam as chances de os pais simplesmente desistirem de registrar seus filhos, consolidando o chamado subregistro de nascimento.

A Lei Federal no 11.790/2008 teve, pois, o mérito de autorizar que o próprio Oficial Registrador possa conduzir o processo, extrajudicialmente.

No entanto, dada a relevância da questão, mostra-se imperioso que os interessados demonstrem ao Oficial Registrador, mediante a produção de provas que instruirão o processo extrajudicial, que não houve registro anterior de nascimento, conforme a atual redação do $\S 3^{\circ}$ do artigo 50 da Lei n ${ }^{\circ} 6.015 / 1973$.

Com efeito, o Provimento n 28/2013 do CNJ prevê a produção das seguintes provas em cartório, a saber:

a) apresentação de Declaração de Nascido Vivo (DNV) original expedida pelo hospital ou maternidade;

b) caso o registrando tenha nascido fora de unidade hospitalar ou maternidade, apresentação da declaração da parteira, conforme $\S 1^{\circ}$ do artigo 52 da Lei no 6.015/73, além da declaração de duas testemunhas desse fato, conforme artigo 54, item $9^{\circ}$, da Lei no 6.015/73;

\footnotetext{
${ }^{18}$ HILL, Flávia Pereira. “A desjudicialização do procedimento de registro tardio de nascimento. Inovações trazidas pela lei federal n. 11.790/08”. Revista Eletrônica de Direito Processual. v.3, p.123 - 133, 2008.
} 
c) oitiva, pelo delegatário ou escrevente autorizado, dos pais do registrando, reduzida a termo, bem como do interessado que instaurou o processo extrajudicial, caso não sejam os pais, indagando-lhes se e por qual razão não lavraram o registro de nascimento até o momento;

d) entrevista, realizada pelo Oficial ou escrevente autorizado, de duas testemunhas, que podem ser parentes do registrando, devendo atestar a identidade do registrando e todas as informações pertinentes de que tenham ciência, sob responsabilidade civil e criminal (artigo $3^{\circ}$, $\mathrm{g}$, Provimento $28 \mathrm{CNJ}$ ). O Oficial deverá verificar se as testemunhas realmente conhecem o registrando, se dispõem de informações concretam e se têm idade compatível com a efetiva ciência dos fatos relevantes (artigo $4^{\circ}$, Provimento $28, \mathrm{CNJ}$ );

e) fotografia do registrando e sua impressão digital, que ficarão arquivadas na serventia (artigo $3^{\circ}$, h, Provimento $28 \mathrm{CNJ}$ ).

f) entrevista, realizada pelo Oficial ou escrevente autorizado, do registrando maior de 12 anos, a fim de apurar se consegue se expressar em português, se conhece razoavelmente a localidade que afirmam ser a sua residência (ruas principais, prédios públicos, bairros, peculiaridades);

g) nas entrevistas, o Oficial ou seu preposto indagará se e onde estudou o registrando e onde costuma obter atendimento médico, se ele possui irmãos, se já se casou, teve filhos e, em caso de resposta positiva, indagar em quais cartórios foram lavrados os registros, se o registrando já teve alguma documentação, tais como carteira de trabalho, habilitação etc, e, em caso afirmativo, apresentá-la.

Cada entrevista será realizada em separado, cabendo ao Oficial ou escrevente autorizado reduzir a termo as declarações colhidas, assinando-o juntamente com o entrevistado (artigo $5^{\circ}$, Provimento $28 \mathrm{CNJ}$ ).

A serventia extrajudicial também poderá diligenciar, a fim de se certificar sobre a ausência de registro de nascimento anterior em outros cartórios. Desse modo, poderá o Oficial Registrador enviar mensagens na intranet, enviar ofício pelo malote digital ou telefonar para o(s) cartório(s) situado(s) no local onde o registrando nasceu e no local da residência de seus pais, à época. As informações obtidas serão reduzidas a termo e constarão do processo extrajudicial. Outro expediente recomendável consiste em proceder a uma pesquisa no site do DETRAN, órgão responsável pela expedição de carteiras de identidade, com vistas a confirmar a ausência de registro de nascimento.

Ao final, o Oficial deverá lavrar minuciosa certidão, "decidindo fundamentadamente pelo registro ou suspeita", conforme artigo $6^{\circ}$ do Provimento 28 do CNJ. Em caso de suspeita, suscitará dúvida ao juiz de direito.

Entendemos que a celebração de atos concertados entre o órgão judicial e a serventia extrajudicial, com fulcro na Resolução 350/2020 do CNJ, de modo a estabelecer protocolos e rotinas comuns de produção de provas no âmbito extrajudicial que possam ser empregadas na esfera judicial, sem a necessidade de sua renovação, caso o Oficial considere não ter sido 
demonstrados os requisitos necessários para a lavratura do registro tardio no processo extrajudicial, representará imenso ganho de tempo, esforços e recursos financeiros.

O mesmo se diga a respeito da produção de provas, perante a serventia extrajudicial, com vistas a instruir o processo extrajudicial de alteração de prenome e gênero em razão da transexualidade, se houver fundada suspeita, pelo Oficial, de fraude, falsidade, má-fé vício de vontade ou simulação quanto ao desejo real da pessoa requerente ou diante da ausência de consentimento dos pais ou do cônjuge do requerente, o que torna a intervenção judicial necessária, na forma dos artigos $6^{\circ}$ e $8^{\circ}, \S^{\circ}$, do Provimento ${ }^{\circ} 73 / 2018$ do CNJ.

De igual sorte, a celebração de atos concertados de instrução probatória entre as esferas judicial extrajudicial seria de grande valia no processo extrajudicial de reconhecimento de paternidade ou maternidade socioafetiva em que haja parecer desfavorável do Ministério Público, no qual o requerente não tenha logrado reunir todo o conjunto probatório previsto em lei ou não tenha havido a concordância dos pais biológicos, obstando, assim, que o delegatário possa praticar o ato sem a intervenção judicial, na forma dos artigos $1^{\circ}, \mathrm{IV}, \mathrm{e} 11, \S 9^{\circ}$, inciso II, do Provimento 83, CNJ.

Outro exemplo ilustrativo consiste na investigação oficiosa de paternidade, prevista no artigo 746, inciso V, do Código de Normas da Corregedoria-Geral de Justiça do Estado do Rio de Janeiro, que determina que a serventia extrajudicial diligencie para apurar a paternidade do registrando, instando o pai a comparecer em cartório.

Entendemos que o órgão judicial e a serventia extrajudicial podem, inclusive, celebrar ato concertado para o compartilhamento da função instrutória, a partir do qual caberá ao oficial a produção de provas que instruirão um processo originariamente instaurado em juízo, de modo a formar o convencimento do juiz, valendo-se, para tanto, da expertise do delegatário da serventia extrajudicial na instrução probatória em procedimentos extrajudiciais afins. Tais atos concertados terão o condão de promover a celeridade e a economia processuais, sem descurar das garantias fundamentais do processo, que são observadas na esfera extrajudicial. Acrescentese que a valoração das provas será realizada pelo magistrado ${ }^{19}$.

Com efeito, Maria Gabriela Campos esclarece que o compartilhamento de competências decorre do consenso entre os órgãos cooperantes, em um modelo cooperativo de processo, sendo autorizado no ordenamento jurídico pátrio, em razão da tendência à flexibilização procedimental prevista pelo legislador nos artigos 139 , inciso IV, 140,536 do CPC/2015 ${ }^{20}$.

A produção, na esfera extrajudicial, de provas que possam ser eficazmente submetidas a posterior cognição judicial, com a dispensa de sua renovação ou complementação no processo

\footnotetext{
${ }^{19}$ Maria Gabriela Campos afirma, com razão, que a celebração de atos de cooperação não significa uma "carta em branco" para que o órgão delegatário pratique o ato "como lhe aprouver", cabendo ao órgão delegante o controle do ato. CAMPOS, Maria Gabriela. O compartilhamento de competências no processo civil: um estudo do sistema de competências sob o paradigma da cooperação nacional. Op. Cit. P. 117.

${ }^{20}$ Idem, ibidem.
} 
judicial, atende aos reclamos por uma maior coordenação e complementaridade entre as duas esferas, promovendo a economia e a eficiência processuais, que são o principal escopo da cooperação judiciária, nela incluída, por certo, a interinstitucional ${ }^{21}$.

Trata-se da atuação concertada e coordenada entre as esferas judicial e extrajudicial, firmes no propósito comum do exercício adequado e eficiente da função jurisdicional em nosso sistema de justiça. Ilustrativo o paralelo com uma corrida de bastões ${ }^{22}$, em que o órgão judicial e o cartório extrajudicial se alternam na prática de atos processuais, sempre de forma coordenada e sincronizada, atentos aos escopos maiores do processo, especialmente pacificar com justiça, observando-se as garantias fundamentais do processo.

A desjudicialização promove o que Rodolfo de Camargo Mancuso intitula, com propriedade, "jurisdição compartilhada" 23 , em que novos núcleos decisórios, dentre os quais os cartórios extrajudiciais, passam a exercer a jurisdição, o que reforça a pertinência do fomento de um crescente "diálogo jurisdicional" 24 entre as esferas judicial e extrajudicial, para que sejam alcançados os fins máximos de nosso sistema de justiça.

De igual modo, consideramos possível que, tratando-se de direito que admita composição, as partes convencionem que a prova produzida em sede de processo extrajudicial (desjudicialização), no qual não tenha sido obtida a providência almejada por ausência de algum requisito legal ou em virtude da manifestação desfavorável do Ministério Público para a sede extrajudicial, possa ser emprestada ao processo judicial instaurado para a mesma finalidade ${ }^{25}$.

Por fim, consideramos perfeitamente possível a celebração de ato de cooperação entre os tribunais e os cartórios extrajudiciais para a prática de outros atos processuais relevantes além da instrução probatória, tais como cientificações e efetivação de medidas executivas atípicas que estejam no espectro das atividades extrajudiciais.

Um expediente, a nosso sentir, nitidamente subaproveitado consiste na possibilidade de ato concertado de cooperação entre os tribunais e os cartórios de Títulos e Documentos para a

\footnotetext{
${ }^{21}$ Idem. p. 118.

${ }^{22}$ Entendemos que as considerações tecidas por Maria Gabriela Campos a respeito da arbitragem, aplicam-se ao compartilhamento de jurisdição entre as esferas judicial e extrajudicial no fenômeno da desjudicialização. Idem, p. 142.

${ }^{23}$ MANCUSO, Rodolfo de Camargo. A resolução dos conflitos e a função judicial no contemporâneo Estado de Direito. Op. Cit. p. 171

${ }^{24}$ CAMPOS, Maria Gabriela. O compartilhamento de competências no processo civil: um estudo do sistema de competências sob o paradigma da cooperação nacional. Op. Cit. p. 144.

${ }^{25}$ Giovani Ravagnani entende que o negócio jurídico processual pode prever o empréstimo da prova mesmo que não tenha havido contraditório simultâneo à sua produção: "Tradicionalmente, a doutrina brasileira sempre exigiu que a prova emprestada pudesse ser utilizada somente contra quem participou de sua formação no processo anterior, sob pena de violação ao contraditório e à ampla defesa. Tal 'exigência', todavia, pode ser superada por convenção processual probatória e pela possibilidade de preservação do contraditório e da ampla defesa, ao se oportunizar a efetiva participação da parte sobre o seu resultado no novo processo". RAVAGNANI, Giovani. Provas negociadas. Convenções processuais probatórias no processo civil. São Paulo: Revista dos tribunais. 2020. pp. 151-152.
} 
realização de atos de cientificação, que seriam revestidos de fé pública. Tais atos de cooperação seriam de grande utilidade, em especial nas comarcas com déficit no número de servidores.

De igual modo, seria de todo recomendável a celebração de convênio entre os tribunais e os cartórios extrajudiciais, com vistas a implementar, em nosso país, a chamada "verificação não judicial qualificada", prevista no artigo 494 do Código de Processo Civil Português ${ }^{26}$.

Trata-se de meio de prova cabível em substituição à inspeção judicial, sempre que se destinar à apuração de fatos de menor complexidade, passíveis de apuração objetiva, e que por isso pode ser realizada por entidade isenta, imparcial e tecnicamente qualificada. Situa-se, portanto, em posição intermediária entre a inspeção judicial e a prova testemunhal. Será cabível quando a inspeção judicial configurar meio de prova desproporcionalmente complexo em comparação com o grau de simplicidade dos fatos a serem verificados e, de outro lado, almeja, diante da imparcialidade e da qualificação do agente que a realizará, a sua apreensão com maior isenção e objetividade do que a prova testemunhal ${ }^{27}$.

Alguns fatores fundamentam, no nosso entender, a possibilidade de realização, no Brasil, da verificação não judicial qualificada pelos cartórios extrajudiciais, notadamente:

(i) a imparcialidade ínsita às atividades desempenhadas pelos cartórios extrajudiciais;

(ii) a fé pública que lhes é inerente (artigo $3^{\circ}$, Lei Federal no $8.935 / 1994$ );

(iii) a finalidade dos cartórios extrajudiciais de conferir publicidade, autenticidade, segurança e eficácia dos atos jurídicos, o que se coaduna com aos objetivos da prova em comento (artigo $1^{\circ}$, Lei Federal no ${ }^{\circ}$ 8.935/1994);

(iv) a experiência dos cartórios extrajudiciais na verificação de fatos, como é o caso, ad exemplum tantum, da ata notarial (artigo 384, CPC/2015) e das diligências realizadas pelo registrador civil para apuração dos fatos que circundam o nascimento (artigo 735, Consolidação Normativa da Corregedoria-Geral de Justiça do Rio de Janeiro); e

(v) a admissibilidade, no ordenamento jurídico-processual brasileiro, de provas atípicas, contanto que moralmente legítimas (artigo 369, CPC/2015).

Sendo assim, constata-se que a cooperação entre as esferas judicial e extrajudicial, ainda tão incipiente, merece ser objeto de maior reflexão em tempos de desjudicialização crescente e de sedimentação da Justiça Multiportas, mormente após a edição da Resolução 350 do CNJ, que alargou o conceito de cooperação judiciária, com vistas a abranger todas as entidades que possam colaborar para a boa administração da justiça.

\footnotetext{
${ }^{26}$ CAPELO, Maria José. "Um novo meio de prova no Código de processo Civil Português de 2013: a verificação não judicial qualificada". Revista ANEEP de Direito processual. Vol I. N. 1. 2020. Janeiro a junho de 2020. p. 130-139.

${ }^{27}$ HILL, Flávia Pereira. Lições do isolamento: reflexões sobre Direito Processual em tempos de pandemia. Rio de Janeiro: edição digital do autor. 2020. Pp. 29-30.
} 
Se, nos dias de hoje, a jurisdição é compartilhada, com o ingresso de novos polos de prestação jurisdicional no centro de nosso sistema de justiça, como é o caso dos cartórios extrajudiciais, o estreitamento da cooperação entre as esferas judicial e extrajudicial se mostra não apenas recomendável, mas premente, em prol do acesso à tutela jurisdicional efetiva e da eficiência de nosso sistema de justiça.

Como dissemos linhas antes, os diferentes operadores do Direito, cada qual em seu âmbito de atuação, precisam se aperceber da importância do "triplo C", de modo a desenvolver, diuturnamente e com crescente afinco, a cooperação, a complementaridade e a coordenação entre suas atuações, tendo em vista que fazemos todos parte do sistema de justiça e estamos todos à serviço do mesmo destinatário: o jurisdicionado.

Se as dificuldades acometem todos nós, enquanto engrenagens dessa gigantesca máquina que é o sistema de justiça brasileiro, os nossos objetivos em comum nos unem e nos levam a concluir que congregar esforços nos deixará mais próximos de sua consecução.

O Conselho Nacional de Justiça, em boa hora, brindou-nos com a Resolução $\mathrm{n}^{\circ}$ $350 / 2020$, que autoriza expressamente a celebração de atos concertados entre as esferas judicial e extrajudicial, inclusive para fins de produção probatória e troca de informações úteis ao processo, preferencialmente por meio eletrônicos, o que privilegia a economia e a eficiência processuais. Cabe a nós, a partir de então, extrair todas as potencialidades práticas do referido regulamento.

\section{CONCLUSÃO}

Tradicionalmente, estamos habituados a pensar e a atuar segundo a lógica do "nós ou eles", conforme ocupemos um cargo dentro ou fora do Poder Judiciário (intra ou extra muros). Pensamos que, se o jurisdicionado deflagrou um processo perante o Poder Judiciário, a princípio, caberá a ele e somente a ele dirigir o processo e nele atuar. Os demais atores, especialmente os cartórios extrajudiciais (eles), serão chamados a atuar eventual e pontualmente. Não haveria, portanto, genuinamente, uma cooperação ou uma condução conjunta.

Nos dias atuais, contudo, faz-se absolutamente indispensável e urgente migrar para uma lógica cooperativa, coordenada e construtiva de atuação: a lógica do "nós $e$ eles". Os diferentes instrumentos contemplados no CPC/2015 e em recentes leis esparsas, assim como a desjudicialização e o novo conceito de jurisdição, em que outros agentes passam ao centro da cena do nosso sistema de justiça, exigem que os operadores do Direito somem as suas forças e atuem coordenada e complementarmente, independentemente de o profissional do Direito estar dentro ou fora do tribunal. Caso ainda não tenhamos nos apercebido, cabe alertar que o legislador pouco a pouco vem demolindo a tradicional dicotomia intra ou extra muros, conforme estejamos dentro ou fora das paredes dos tribunais. 
A genuína consciência de que somos um único grupo de trabalho (Arbeitsgemeinschaft, no termo alemão); cada qual uma engrenagem dessa gigantesca máquina que é o nosso sistema de justiça, é uma premissa inexorável, senão de todos, dos principais instrumentos e institutos previstos nas leis processuais dos últimos anos, inclusive e principalmente da desjudicialização.

A experiência de 15 anos de atuação em cartório extrajudicial, com contato direto com o jurisdicionado, nos fez aprender que o homem médio não distingue Juiz, Promotor, Defensor ou Delegatário. Quando ele profere a (infelizmente) conhecida frase "A Justiça no Brasil não funciona”, a crítica é endereçada a todos nós, indistintamente; que não restem dúvidas disso.

Portanto, o inimigo é único: a ineficiência e a morosidade do sistema de justiça. O desiderato também é único: prestar a jurisdição adequadamente.

O Conselho Nacional de Justiça, ao editar a Resolução $n^{\circ} 350 / 2020$, acertadamente amplia o conceito de cooperação judiciária, deixando claro que, na atualidade, abrange todas as entidades que possam contribuir para a boa administração da justiça, o que, sem sombra de dúvidas, alcança as serventias extrajudicial no atual contexto da desjudicialização.

Sendo assim, muito útil se afigura a celebração de atos concertados entre órgão judicial e serventia extrajudicial nos processos extrajudiciais, a fim de que, que, aproveitando as vantagens das novas tecnologias, propiciem o emprego do arcabouço probatório produzido no âmbito extrajudicial para fins de convencimento do magistrado no processo judicial. Inúmeros exemplos cotidianos ilustram quão proveitosa seria a iniciativa, a bem da economia e da celeridade processuais, evitando-se a repetição de atos.

Fazer com que a desjudicialização se aprimore e funcione a contento trará benefícios ao Poder Judiciário, que poderá se concentrar na solução dos litígios para os quais realmente se afigura como o método mais adequado, e para a sociedade, que finalmente poderá obter a prestação jurisdicional - seja perante o Poder Judiciário, seja nos novos polos de prestação da jurisdição - de forma mais célere e efetiva, sem abrir mão das garantias fundamentais do processo.

Não é um caminho simples; ninguém disse que o seria. Mas as conquistas, se alcançadas, serão perenes e para todos.

\section{REFERÊNCIAS}

ASSIS, Carolina Azevedo. "Desjudicialização a execução civil: um diálogo com o modelo português". In MEDEIROS NETO, Elias Marques de. RIBEIRO, Flávia Pereira. Reflexões sobre a Desjudicialização da Execução Civil. Curitiba: Juruá. 2020. pp. 75-104.

ASSOCIAÇÃO DE NOTÁRIOS E REGISTRADORES DO BRASIL. Cartório em números. Disponível no endereço eletrônico: 
https://anoreg.org.br/anoregbr_file/Cart\%C3\%B3rio\%20em\%20N\%C3\%BAmeros.pdf Consulta realizada em 09/03/2020.

CAMPOS, Maria Gabriela. O compartilhamento de competências no processo civil: um estudo do sistema de competências sob o paradigma da cooperação nacional. Salvador: Jus Podivm. 2020.

CANTOARIO, Diego Martinez Fervenza. “Considerações sobre o Projeto de Lei 5080/2009: a nova lei de Execução Fiscal”. Revista Tributária e de Finanças Públicas. Número 91. Março-Abril 2010. pp. 11-42.

CAPELO, Maria José. "Um novo meio de prova no Código de processo Civil Português de 2013: a verificação não judicial qualificada". Revista ANEEP de Direito processual. Vol I. N. 1. 2020. Janeiro a junho de 2020. p. 130-139.

CARNEIRO, Paulo Cezar Pinheiro. "Acesso à justiça: Juizados Especiais Cíveis e Ação Civil Pública. Uma nova sistematização da Teoria Geral do Processo.” 2. Ed. Rio de Janeiro: Forense, 2000.

CENEVIVA, Walter. Lei dos Registros Públicos Comentada. 15. Ed. São Paulo: Editora Saraiva. 2002. p. 400.

CONSELHO NACIONAL DE JUSTIÇA. Justiça em números 2019. Disponível em https://www.cnj.jus.br/wpcontent/uploads/conteudo/arquivo/2019/08/justica_em_numeros20190919.pdf Consulta realizada em 05/06/2020.

CONSELHO NACIONAL DE JUSTIÇA. Provimento $n^{\circ}$ 89, de 18/12/2019. Disponível no endereço eletrônico: https://atos.cnj.jus.br/files/original173255201912195dfbb44718170.pdf Consulta realizada em 09/03/2020.

CONSELHO NACIONAL DE JUSTIÇA. Provimento $n^{\circ}$ 65/2017. Disponível em: https://atos.cnj.jus.br/files//provimento/provimento_65_14122017_19032018152531.pdf Consulta realizada em 14/07/2020. Consulta realizada em 10/03/2021.

CONSELHO NACIONAL DE JUSTIÇA. Provimento $n^{o}$ 73/2018. Disponível em: https://www.cnj.jus.br/wpcontent/uploads/2018/06/434a36c27d599882610e933b8505d0f0.pdf Consulta realizada em $10 / 03 / 2021$.

CONSELHO NACIONAL DE JUSTIÇA. Provimento $n^{\circ}$ 28/2013. Disponível em: https://atos.cnj.jus.br/files//provimento/provimento_28_05022013_25042013154655.pdf Consulta realizada em 10/03/2021.

CONSELHO NACIONAL DE JUSTIÇA. Provimento $n^{o}$ 83/2019. Disponível em: https://atos.cnj.jus.br/files//provimento/provimento_83_14082019_15082019095759.pdf Consulta realizada em 10/03/2021. 
CONSELHO NACIONAL DE JUSTIÇA. Resolução $n^{o}$ 350/2020. Disponível em:

https://atos.cnj.jus.br/files/original182611202011035fa1a0c3a36f6.pdf Consulta realizada em 10/03/2021.

CORREGEDORIA-GERAL DE JUSTIÇA DO ESTADO DE SÃO PAULO. Processo ${ }^{\circ}$ 2020/38240. https://infographya.com/files/20200417_DECISAO__CONVENIO_ARISP_ARPENSP.pdf Consulta realizada em 17/08/2020.

CUNHA, Leonardo Carneiro da. "A previsão do princípio da eficiência no projeto do novo Código de Processo Civil brasileiro”. Revista de Processo. vol. 233. Jul. 2014. pp. 65-84.

DIDIER JUNIOR, Fredie. Cooperação judiciária nacional: esboço de uma teoria para o Direito brasileiro (arts. 67-69, CPC). Salvador: Jus Podivm. 2020.

DINAMARCO, Cândido Rangel. Instituições de Direito Processual Civil. Vol. I. 8. Ed. São Paulo: Malheiros. 2016.

FARIA, Marcio Carvalho. Primeiras impressões sobre o PL 6.204/2019: a tentativa de se desjudicializar a execução civil brasileira. 2020. p. 37. Trabalho de conclusão do pósdoutorado em Direito Processual Civil perante a Universidade Federal da Bahia, gentilmente cedido pelo autor.

FIGUEIRA JUNIOR, Joel Dias. “Desjudicialização da Execução Civil”. Disponível em https://www.migalhas.com.br/depeso/330308/desjudicializacao-da-execucao-civil Consulta realizada em 08/07/2020.

GRECO, Leonardo. "As garantias fundamentais do processo na execução fiscal”. In LOPES, João Batista. CUNHA, Leonardo José Carneiro da (coords). Execução Civil (aspectos polêmicos). São Paulo: Dialética. 2005.

HILL, Flávia Pereira. PINHO, Humberto Dalla Bernardina de. "Inventário Judicial ou extrajudicial; separação e divórcio consensuais por escritura pública - primeiras reflexões sobre a Lei n. 11.441/07'. Revista Dialética de Direito Processual. V. 50. Maio-2007. pp. 4259.

HILL, Flávia Pereira. “A desjudicialização do procedimento de registro tardio de nascimento. Inovações trazidas pela lei federal n. 11.790/08”. Revista Eletrônica de Direito Processual. V. 3. Ano 3. Jan-Jun 2009. pp. 123-133.

HILL, Flávia Pereira. “Considerações sobre a cooperação jurídica internacional no novo Código de Processo Civil”. MACÊDO, Lucas Buril. PEIXOTO, Ravi. FREIRE, Alexandre. Coleção novo CPC Doutrina Selecionada. Vol. 1. Parte Geral. 2. Ed. Salvador: Editora Jus Podivm. 2016. pp. 743-766.

HILL, Flávia Pereira. “O procedimento extrajudicial pré-executivo (Pepex): reflexões sobre o modelo português, em busca da efetividade da execução no Brasil”. In MEDEIROS NETO, Elias Marques de. RIBEIRO, Flávia Pereira. Reflexões sobre a Desjudicialização da Execução Civil. Curitiba: Juruá. 2020. pp. 305-322. 
HILL, Flávia Pereira. O Direito Processual Transnacional como forma de acesso à justiça no século XXI: os reflexos e os desafios da sociedade contemporânea para o Direito Processual Civil e a concepção de um título executivo transnacional. Rio de Janeiro: GZ Editora. 2013.

HILL, Flávia Pereira. "Mediação nos cartórios extrajudiciais: desafios e perspectivas". Revista Eletrônica de Direito Processual. Volume 19, número 3. Set/dez 2018. pp. 296-323.

HILL, Flávia Pereira. A antecipação de tutela no processo de homologação de sentença estrangeira. Rio de Janeiro: GZ Editora. 2010.

HILL, Flávia Pereira Hill. Palestra online Desafios dos Juizados Especiais Cíveis durante e após a pandemia de Covid-19. Texto disponível no endereço eletrônico:

https://www.academia.edu/43755163/PALESTRA_ONLINE_DESAFIOS_DOS_JUIZADOS ESPECIAIS_C\%C3\%8DVEIS_DURANTE_E_AP\%C3\%93S_A_PANDEMIA_DE_COVI

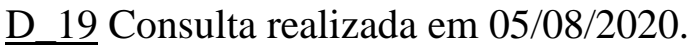

HILL, Flávia Pereira. BEM, Camila Bissoli do. CAMPISTA, Fabio. "A duração razoável do processo e os parâmetros jurisprudenciais dos tribunais internacionais de direitos humanos". In Revista Brasileira de Direito Processual. ano 25. n. 99. julho/setembro 2017. Belo Horizonte. pp. 111-143.

HILL, Flávia Pereira. "Desjudicialização da execução civil: reflexões sobre o Projeto de Lei n ${ }^{\circ}$ 6.204/2019". Revista Eletrônica de Direito Processual. Volume 21, número 3. Setembrodezembro 2020.

HILL, Flávia Pereira. Lições do isolamento: reflexões sobre Direito Processual em tempos de pandemia. Rio de Janeiro: edição digital do autor. 2020.

GOLDBERG, Stephen B. SANDER, Frank E. A. ROGERGS, Nancy H. COLE, Sarah Rudolph. Dispute Resolution. 4. Ed. Nova York: Aspen Publishers. 2003.

INSTTUTO DOS ADVOGADOS DO BRASIL. Parecer sobre o Projeto de Lei do Senado $n^{o}$ 6.204/2019, de autoria da Senadora Soraya Thronicke (PSL/MS).

LOUREIRO, Luiz Guilherme. Registros Públicos. Teoria e Prática. 3. Ed. São Paulo: GEN Método. 2012.

LUNARDI, Thais Amoroso Paschoal. Coletivização da prova. Técnicas de produção coletiva da prova e seus reflexos na esfera individual. Tese de Doutorado em Direito das Relações Sociais no Programa de Pós- Graduação da Faculdade de Direito da Universidade Federal do Paraná. 2018.

MANCUSO, Rodolfo de Camargo. A resolução dos conflitos e a função judicial no contemporâneo estado de Direito. 2. Ed. São Paulo: Revista dos Tribunais. 2013.

MARQUES, Cláudia Lima. “A teoria do 'diálogo das fontes' hoje no Brasil e seus novos desafios”. MARQUES, Cláudia Lima. MIRAGEM, Bruno (Coords). Diálogo das fontes. Novos estudos sobre a coordenação e aplicação das normas no Direito Brasileiro. São Paulo: Revista dos Tribunais. 2020. 
MAXIMILIANO, Carlos. Hermenêutica e aplicação do direito.19. ed. Rio de Janeiro: Forense. 2006.

MEDEIROS NETO, Elias Marques de. "O CPC/2015 e a busca antecipada de bens do patrimônio do devedor”. In Revista de Processo. vol. 271. Set. 2017 pp. 155-177.

MEDEIROS NETO, Elias Marques de. "A recente Portaria 33 da Procuradoria-Geral da Fazenda Nacional, a Lei 13.606/18 e o PePex português: movimentos necessários de busca antecipada de bens do devedor". In Revista de Processo. vol. 281. São Paulo: Revista dos Tribunais. Jul. 2018.

OLIVEIRA, Daniela Olímpio de. "Uma releitura do princípio do acesso à justiça e a ideia da desjudicialização”. Revista Eletrônica de Direito Processual. Volume 11. Pp. 67-98.

PASSOS, José Joaquim Calmon de. O problema do acesso à justiça no Brasil. Revista de Processo. vol. 39/1985. Jul-Set 1985. pp. $78-88$.

PASSOS, José Joaquim Calmon de. Direito, poder, justiça e processo. Rio de Janeiro: Forense. 2000.

PINHO, Humberto Dalla Bernardina de. "A nova fronteira do acesso à justiça: a jurisdição transnacional e os instrumentos de cooperação internacional no CPC/2015". Revista Eletrônica de Direito Processual. Volume 18, número 2. Maio-Agosto 2017. pp. 261-296.

PINHO, Humberto Dalla Bernardina de. PORTO, José Roberto Mello. “A desjudicialização enquanto ferramenta de acesso à justiça no CPC/2015: a nova figura da usucapião por escritura pública". Revista Eletrônica de Direito Processual. Volume 17, número 2. JulhoDezembro 2016. pp. 320-353.

PINHO, Humberto Dalla Bernardina de. "A releitura do princípio do acesso à justiça e o necessário redimensionamento da intervenção judicial na resolução dos conflitos na contemporaneidade". In Revista Jurídica Luso-brasileira. Ano 5. Número 3. 209. pp. 791830 .

RAVAGNANI, Giovani. Provas negociadas. Convenções processuais probatórias no processo civil. São Paulo: Revista dos tribunais. 2020. pp. 151-152.

TALAMINI, Eduardo. “A prova emprestada no processo civil e penal”. Revista de Informação Legislativa. Brasília a. 35 n. 140 out./dez. 1998. pp. 145-162.

VALENTE, Jonas. Agência Brasil. Brasil tem 134 milhões de usuários de internet, aponta pesquisa. Disponível no endereço eletrônico:

https://agenciabrasil.ebc.com.br/geral/noticia/2020-05/brasil-tem-134-milhoes-de-usuariosde-internet-aponta-pesquisa Consulta realizada em 05/08/2020.

WALD, Arnoldo. “A reforma da lei de arbitragem”. Revista dos Tribunais. vol. 962. p. 195 216. Dez/2015. 